\title{
The Effects of Age on Substrate Depletion and Hormonal Responses During Submaximal Exercise in Hamsters
}

\author{
JEANNE F. NICHOLS ${ }^{1}$ AND KATARINA T. BORER \\ Department of Kinesiology, The University of Michigan, Ann Arbor, MI 48109
}

Received 10 April 1987

\begin{abstract}
NICHOLS, J. F. AND K. T. BORER. The effects of age on substrate depletion and hormonal responses during submaximal exercise in hamsters. PHYSIOL BEHAV 41(1) 1-6, 1987.-Senescent hamsters display a marked reduction in volume of voluntary running. The purpose of this study was to determine whether age differences exist in the pattern of fuel utilization during submaximal exercise, which may account for the reduction in voluntary running. Further, we determined the effects of age on muscle oxidative capacity to assess its relationship to endurance performance in senescent hamsters. Depletion of carbohydrate and lipid content of skeletal muscle and liver, and changes in blood concentration of various hormones and substrates during one hour of exercise at 60 percent of $\mathrm{VO}_{2}$ max served to assess age effects on utilization of metabolic substrates. Exercise produced equivalent depletion of muscle glycogen and similar rise in plasma free fatty acids in young and old hamsters. No exercise effects on skeletal muscle triglyceride concentration or on plasma glycerol, glucagon or catecholamine concentrations were noted. With palmitoyl carnitine as substrate (but not with pyruvate) State 3 respiration of cardiac and skeletal muscle homogenates was lower in old compared to young hamsters. Although old hamsters have a reduced capacity to oxidize lipids in vitro, few age differences in fuel use are evident in vivo during submaximal exercise. Thus, these minor age differences in substrate utilization do not likely account for the substantial reduction in the levels of spontaneous running in senescent hamsters.
\end{abstract}

Aging Substrate utilization Oxidative capacity Endurance exercise

WITH advancing age there is a decline in the capacity of animals and man to adjust to stresses such as exercise. Ageassociated decrements in aerobic capacity and endurance performance reflect reduced capacity for both intense and prolonged exercise $[2,24]$. Since the availability and type of fuel used during exercise place limitations on both the intensity and duration of physical activity, a possible explanation for the age-associated decline in physical performance may reside in differences in the availability of energy substrates and/or changes in the types of fuels used by contracting skeletal muscle.

In physical activities of a prolonged nature performed at submaximal intensity, free fatty acids (FFA) are a major source of energy for the contracting muscle. Experimental inhibition of FFA mobilization during submaximal exercise leads to greater dependence on carbohydrates as a fuel, and to earlier onset of fatigue as carbohydrate stores are depleted [26]. Even in the absence of such experimental manipulations, some carbohydrate utilization is obligatory during endurance exercise, and muscle glycogen content determines both the pace and duration of prolonged submaximal exercise $[5,19]$.

In laboratory rats, age-associated changes that may influ- ence fuel utilization by contracting muscle include decreased adipocyte sensitivity to lipolytic hormones [16] and decrements in mitochondrial content and respiration in cardiac and skeletal muscle $[7,13,18]$.

Golden hamsters are particularly suitable for studies of the effects of aging on endurance activities because they spontaneously run great distances $(6-10 \mathrm{~km} / \mathrm{night})$ [9] at the submaximal pace of about 60 percent of maximal oxygen uptake (unpublished data). Senescent hamsters display approximately a 50 percent reduction in volume of voluntary running activity (to be published). Our purpose was to determine whether decrements in either the availability and utilization of substrates or the muscles's capacity to oxidize those substrates account for the decline in spontaneous running activity in senescent hamsters.

\section{METHOD}

\section{Animals and Maintenance}

Female golden hamsters (Mesocricetus auratus) were obtained as retired breeders from Engle Laboratory Animals, Farmersburg, IN, at the age of eight to nine months and body weight of $145 \pm 4.6$ grams (mean \pm S.E.M.). At sacrifice body 1Requests for reprints should be addressed to Jeanne F. Nichols, Department of Physical Education, San Diego State University, San
Diego, CA 92182. 
weight of old animals was $138 \pm 4.5$ grams. Old hamsters were maintained in our animal facility until the age of 16-17 months. The mean lifespan for the female of thi species is approximately $12-16$ months, depending on nutritional and environmental factors $[1,8]$; therefore, animals utilized in the study were older than the reported mean lifespan for this species. Young adult control animals were obtained from the same breeder at the age of two to three months and body weights of 90-100 grams, and were used for experimentation two weeks later. At sacrifice body weight of young animals was $112 \pm 1.6$ grams (mean \pm S.E.M.). All animals were housed individually in suspended cages with wire bottoms under controlled temperature $\left(21-22^{\circ} \mathrm{C}\right)$ and light (12 L:12 D) and with unlimited access to water and Purina 5008 Formulab Chow pellets. Old animals were maintained under similar living conditions prior to arrival in our facility. Animals that demonstrated large, unexplained weight loss or signs of pathology were excluded from these experiments.

\section{$\mathrm{VO}_{2}$ max Determination}

To select a workload of the same relative intensity for young and old animals in the substrate depletion experiment, a maximal oxygen uptake $\left(\mathrm{VO}_{2} \max \right)$ test was performed. $\mathrm{VO}_{2}$ max was determined in eight young and eight old hamsters by means of a metabolic chamber, using a rapid flow open circuit system [11]. Oxygen and carbon dioxide concentrations were measured with the respective analyzers (Ametek Co., Sunnyvale, CA), which were connected online to a Cromemco System Three microcomputer which recorded percent oxygen and percent carbon dioxide. $\mathrm{VO}_{2}$ and $\mathrm{VCO}_{2}$ were calculated as for humans, using the premise of pulmonary nitrogen equality in ventilation and the Haldane transformation [14]. Animals were habituated to treadmill running and the metabolic chamber for 10 minutes each of three consecutive days prior to the $\mathrm{VO}_{2} \max$ assessment. Each animal underwent a progressive exercise test to exhaustion utilizing the following protocol: for young animals, after a five minute warm-up at $13.1 \mathrm{~m} / \mathrm{min}$, the treadmill speed was increased by $3.4 \mathrm{~m} / \mathrm{min}$ every two minutes until the animal could no longer run. The warm-up speed for old animals was $10.5 \mathrm{~m} / \mathrm{min}$, but speed increments were the same as for young-adult animals. The elevation of the treadmill was maintained at 10 percent grade throughout the test. The test was terminated when the animal failed to run or leave the shock grid for one complete stage.

\section{Substrate Depletion Experiment}

Four independent groups of animals were used in this experiment: young non-exercised $(n=6)$, young exercised $(n=6)$, old non-exercised $(n=6)$, and old exercised $(n=6)$. Approximately two weeks after the $\mathrm{VO}_{2} \max$ assessment hamsters underwent a single 60 minute bout of treadmill running at 60 percent of $\mathrm{VO}_{2} \max$. This corresponded to speeds of $13.1 \mathrm{~m} / \mathrm{min}$ and $11.0 \mathrm{~m} / \mathrm{min}$ for young and old animals, respectively, at three percent grade. This grade was selected because it approximates the angle of the disc used in spontaneous running [9].

Food was removed from non-exercised animals one hour before sacrifice, and from exercised animals at the start of the treadmill run. Blood and tissue samples were obtained from the four groups at 0 and 60 minutes of exercise in alternating order, following anesthesia with pentobarbital sodium $(75 \mathrm{mg} / \mathrm{kg}$, IP). Blood was collected from the abdominal dorta into a $5 \mathrm{ml}$ syringe, alıquotted into chilled heparınızed tubes to obtain plasma, nonheparinized tubes to obtan serum, or untreated tubes to which eight percent perchloric acid was added to remove blood proteins for determination of glycerol.

Immediately following blood collection, one quadriceps muscle and one lobe of liver were dissected and frozen in dry ice-1sopentane, then stored at $-70^{\circ} \mathrm{C}$. All procedures were conducted within 10 minutes from the time of anesthesia.

Asirish

To measure glycogen concentration a section of quadriceps muscle was dissected free of adipose and connective tissue, then homogenized in 10 volumes of $0.6 \mathrm{~N}$ perchloric acid, while a section of liver was homogenized in five volumes of the same. Glycogen in $200 \mu$ l of homogenate was hydrolized with amyloglucosidase [21]. For liver, the remaining homogenate was centrifuged for 10 minutes at $1500 \times \mathrm{g}$ and the supernatant used to determine endogenous free glucose by the fluorometric procedure [22]. Following hydrolysis with amyloglucosidase, homogenates were centrifuged 10 minutes at $1500 \times \mathrm{g}$, and glucose determined by the same procedure.

For muscle triglyceride, a section of quadriceps muscle was dissected free of adipose and connective tissue, then homogenized in nine volumes of $10 \mathrm{mM}$ sodium phosphate buffer, $\mathrm{pH}$ 7.4. The triglyceride was extracted with heptane and 2-propanol (2.0/3.5) [29]. The non-polar upper phase was treated with $0.1 \mathrm{~N} \mathrm{NaOH}$ in 2-propanol to liberate glycerol, which was then oxidized with $0.018 \mathrm{~N}$ sodium periodate, which in turn was reacted with acetylacetone and ammonium ions to produce a lutidine derivative with a maximum absorbance at $415 \mathrm{~nm}$.

Free fatty acids were extracted with a chloroformheptane-methanol reagent. The FFA, contained within the non-polar upper layer of the extract, reacted with ferrous ions in a triethanolamine solution to form copper salts, which were then reacted with sodium salts of diethyldithiocarbamic acid to form a colored product, which was measured spectrophometrically [15]. Serum glucose was measured by the glucose oxidase method, using a standard Statzyme Kit from Worthington Diagnostics. Serum glycerol was assayed by an enzymatic procedure [4]. Glycerol in deproteinized sera was converted to alpha glycerophosphate by ATP and glycerokinase. Glycerophosphate was then oxidized by NAD-dependent alpha glycerophosphate dehydrogenase (GPDH). The reduced NADH was measured fluorometrically.

Blood urea nitrogen (BUN) and urine protein were determined at sacrifice as indicators of total body protein loss, which served as a gross marker of pathology. Uristix, for determination of urine protein, and azostix, for determination of whole blood urea nitrogen were purchased from Ames Division of Miles Laboratories. Animals that displayed unusually high levels of BUN and urine protein were excluded from data analyses.

\section{Hormone Determinations}

Insulin was assayed by a double antibody radioimmunoassay technique using an antibody against porcine insulin, developed in a guinea pig, labelled porcine insulin and a purified rat insulin standard (Eli Lilly Research Labs) [6]. Assay sensitivity was $11.9 \pm 3.4 \mathrm{pg} / \mathrm{ml}$, and interassay coefficient of variation for a standard hamster serum was 17.9 


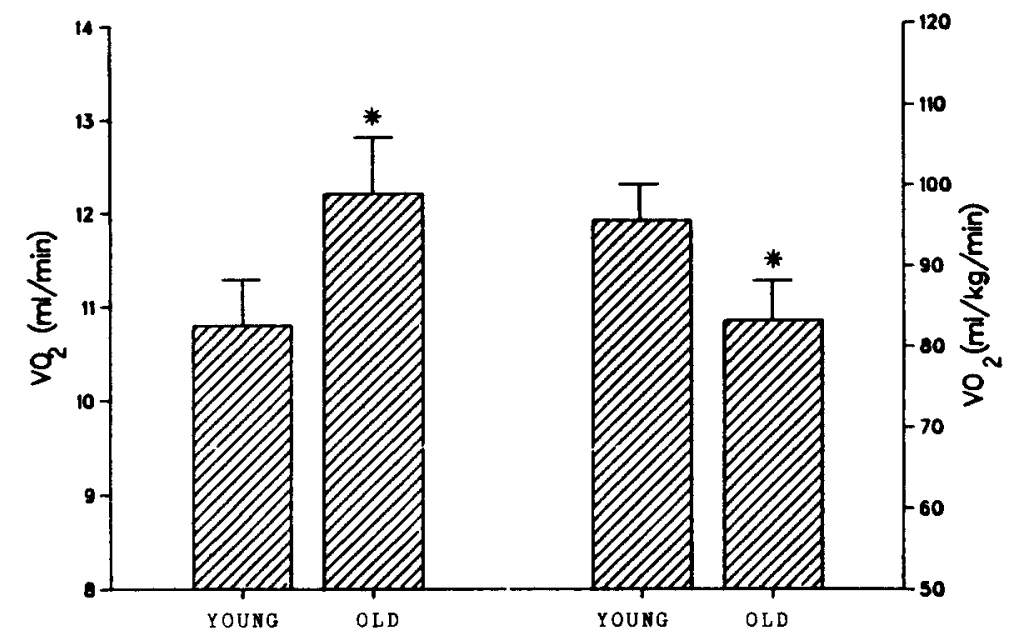

FIG. 1. Maximal oxygen consumption in young and old hamsters. Values are mean \pm S.E.M. ${ }^{*} p<0.05$ compared to young.

TABLE 1

AGE EFFECTS ON SERUM, SKELETAL MUSCLE AND LIVER SUBSTRATES FOLLOWING 1 HOUR OF SUBMAXIMAL TREADMILL RUNNING

\begin{tabular}{lcccc}
\hline & \multicolumn{2}{c}{ Young $(\mathrm{n}=6)$} & \multicolumn{2}{c}{ Old $(\mathrm{n}=6)$} \\
Substrate & Non-Exercise & Exercise & Non-Exercise & Exercise \\
\hline $\begin{array}{l}\text { Quadriceps Glycogen } \\
(\mathrm{mg} / \mathrm{g} \text { wet mass) }\end{array}$ & $11.7 \pm 1.7$ & $9.3 \pm 2.0^{*}$ & $14.4 \pm 1.2+$ & $11.7 \pm 2.6^{*}$ \\
$\begin{array}{c}\text { Quadriceps Triglyceride } \\
(\mu \mathrm{mol} / \mathrm{g} \text { wet mass) }\end{array}$ & $11.0 \pm 1.1$ & $9.58 \pm 1.9$ & $8.62 \pm 1.2$ & $7.44 \pm 0.76$ \\
$\begin{array}{c}\text { Liver Glycogen } \\
(\mathrm{mg} / \mathrm{g} \text { wet mass) }\end{array}$ & $48.0 \pm 4.2$ & $36.8 \pm 2.4^{*}$ & $30.0 \pm 5.3 \dagger$ & $26.35 \pm 5.9$ \\
$\begin{array}{c}\text { Serum Glucose } \\
(\mathrm{mg} / \mathrm{dl})\end{array}$ & $87.5 \pm 8.0$ & $113.0 \pm 6.4^{*}$ & $143.1 \pm 3.0^{+}$ & $140.0 \pm 5.7$ \\
$\begin{array}{c}\text { Serum FFA } \\
(\mu \mathrm{M})\end{array}$ & $31.2 \pm 4.5$ & $52.0 \pm 7.7^{*}$ & $32.33 \pm 8.3$ & $63.6 \pm 10.6^{*}$ \\
$\begin{array}{l}\text { Serum Glycerol } \\
(\mu \mathrm{M})\end{array}$ & $87.0 \pm 4.0$ & $96.0 \pm 8.1$ & $84.0 \pm 10.0$ & $94.0 \pm 10.0$ \\
\hline
\end{tabular}

Values are mean \pm S.E.M.

${ }_{p}^{*}<0.05$ compared to Non-Exercised.

$\dagger p<0.05$ compared to Young Non-Exercised.

percent. Glucagon was measured by The Michigan Diabetes Research Training Center by radioimmunoassay [25]. Assay sensitivity was $2.8 \mathrm{pg} / \mathrm{ml}$, and interassay coefficient of variation was 5 percent. Plasma catecholamines were assayed by The Michigan Diabetes Research Training Center using high performance liquid chromatography technique [17]. Detection limits of the assay were $4 \mathrm{pg}$ for norepinephrine and $8 \mathrm{pg}$ for epinephrine.

\section{Oxidative Capacity of Muscle Homogenates}

In a separate experiment oxidative capacity of quadriceps muscle and heart was determined from a cohort of young $(n=6)$ and old $(n=6)$ animals. Following anesthesia with pentobarbital sodium ( $75 \mathrm{mg} / \mathrm{kg}, \mathrm{IP}$ ), the quadriceps muscle and heart were dissected free of connective and adipose tissue, blotted then weighed and cooled in nine volumes of ice-cold homogenizing medium (175 mM KCl, 2 mM EDTA, pH 7.4). Oxidative capacity of $0.15 \mathrm{ml}$ of homogenate was determined with pyruvate, then with palmitoyl carnitine as substrate [20]. All reactions were initiated within 15 minutes of obtaining the tissues. Oxygen consumption was measured in a YSI model 53 Oxygen Monitor System and recorded on a Beckman recorder. Reactions were carried out at $37^{\circ} \mathrm{C}$ with the following reaction system for pyruvate oxidation: $150 \mu \mathrm{l}$ of homogenate was added to $1 \mathrm{ml}$ of reaction medium, containing (in $\mathrm{mM}$ ): $\mathrm{KCl}, 87.5 ; \mathrm{KHPO}_{4}, 40 ; \mathrm{MgCl}_{2}, 5$; EDTA, 1.6; cytochrome C, 0.078; sucrose, 50; ADP, 2.0; malate, 1.0 ; pyruvate, $2.5 ; \mathrm{pH} 7.4$. For palmitoyl-carnitine oxidation: $75 \mathrm{mM}$ plamitoyl-carnitine and $24 \mathrm{mM}$ albumin were substituted for pyruvate, after first being sonicated for approximately 20 seconds. All other mixtures were kept the same. Basal rates due to the oxidation of endogenous substrates in the presence of ATP were subtracted from the rates with 
TABLE 2

AGE EFFECTS ON SERUM HORMONAL RESPONSES FOLLOWING 1 HOUR OF SUBMAXIMAL TREADMILL RUNNING

\begin{tabular}{lcccc}
\hline & \multicolumn{2}{c}{ Young $(\mathrm{n}=6)$} & \multicolumn{2}{c}{ Old $(\mathrm{n}=6)$} \\
Hormone & Non-Exercise & Exercise & Non-Exercise & Exercise \\
\hline $\begin{array}{l}\text { Insulin } \\
(\mathrm{ng} / \mathrm{ml})\end{array}$ & $5.42 \pm 0.88$ & $2.8 \pm 0.6^{*}$ & $1.8 \pm 0.48^{\dagger}$ & $2.4 \pm 1.0$ \\
$\begin{array}{c}\text { Glucagon } \\
(\mathrm{pg} / \mathrm{ml})\end{array}$ & $260 \pm 44.8$ & $207 \pm 21.0$ & $466 \pm 78.3 \dagger$ & $406 \pm 51.9 \dagger$ \\
$\begin{array}{c}\text { Epinephrine } \\
(\mathrm{ng} / \mathrm{ml})\end{array}$ & $2.3 \pm 0.12$ & $2.6 \pm 0.6$ & $1.5 \pm 0.02$ & $1.9 \pm 0.7$ \\
$\begin{array}{c}\text { Norepinephrine } \\
(\mathrm{ng} / \mathrm{ml})\end{array}$ & $5.6 \pm 0.9$ & $5.6 \pm 0.8$ & $5.2 \pm 0.2$ & $4.2 \pm 0.8$ \\
\hline
\end{tabular}

Values are mean \pm S.E.M.

${ }^{*} p<0.05$ compared to Non-Exercised.

$t_{p}<0.05$ compared to Young Non-Exercised.

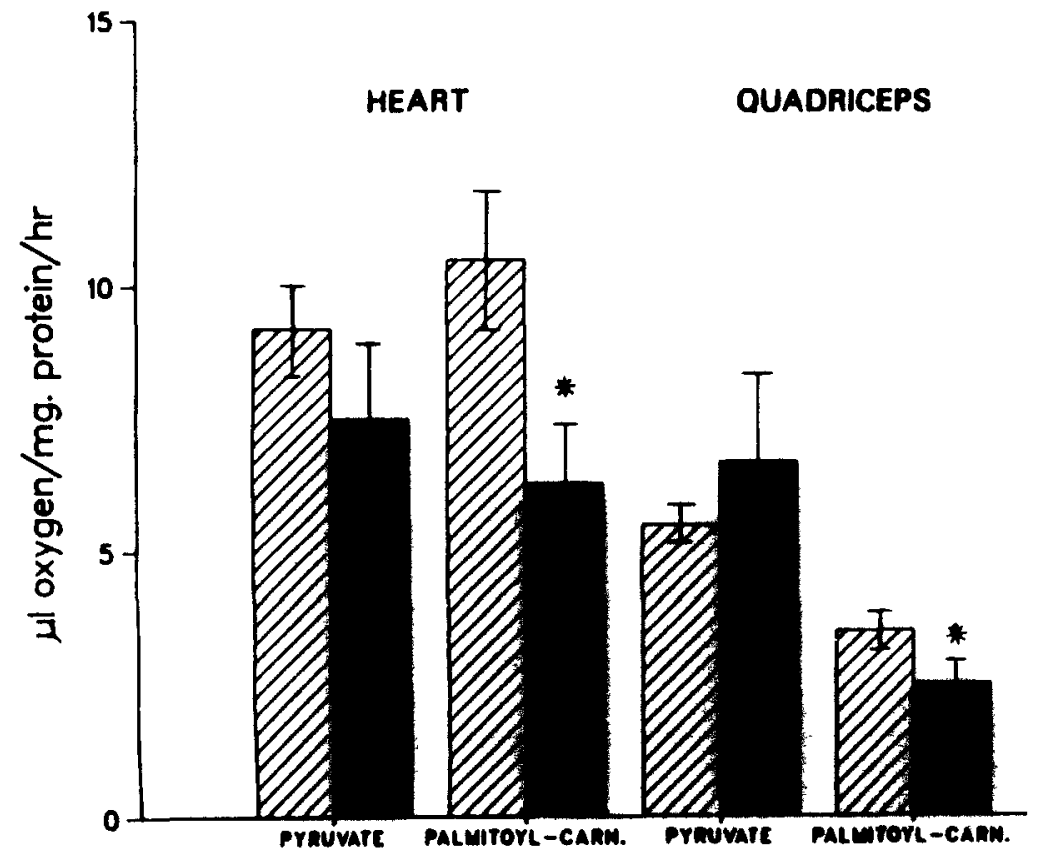

FIG. 2. Oxıdative capacity of cardiac and skeletal muscle homogenates trom young and old hamsters. Values are mean \pm S.E.M. ${ }^{*} p<0.05$ compared to young oxidizing the same substrate.

substrate added. Protein concentration was determined with the remaining homogenate [23].

\section{Statistical Analyses}

All data values are expressed as mean \pm S.E.M. Significant differences between group values for the substrate depletion experiment were determined by a two-way ANOVA and a Tukey post-hoc analysis. Significant differences between groups for $\mathrm{VO}_{2} \max$ and muscle oxidative capacity were determined by a Student $t$-test. The criterion for statistical significance was set at $p<0.05$.
RESULTS

$V O_{2} \max$

Maximal oxygen consumption, expressed as a function of body weight, was 14 percent lower in old hamsters compared to young, $(p<0.05)$ (Fig. 1). Due to body weight differences, absolute $\mathrm{VO}_{2} \max$ values were greater in old than in young animals.

\section{Substrate Depletion Experiment (Table 1)}

The following age-related differences in the concentra- 
tions of stored and circulating substrates were noted: glycogen concentration in quadriceps was higher, and in the liver was lower in old compared to young hamsters, while serum glucose concentration was higher in old than in young hamsters. Exercise-induced glycogen depletion was similar in old and in young hamsters. Likewise, exercise-induced increases in serum free fatty acids were comparable in old and young hamsters. Exercise induced a 25 percent decrease in liver glycogen concentration in young hamsters, but had no effect in old. Serum glucose concentration increased by 30 percent in exercising young, but was unchanged in exercising old hamsters.

\section{Hormones (Table 2)}

Serum insulin concentration was significantly lower, while serum glucagon was significantly higher in old, nonexercised animals, compared to young. Exercise had no effect on serum insulin concentration in old animals, but suppressed serum insulin in young animals to the level seen in non-exercised old animals $(p<0.05)$. Serum glucagon and plasma catecholamines were unaffected by exercise in both young and old hamsters.

\section{Oxidative Capacity of Muscle Homogenates}

The oxidative capacity of both cardiac and skeletal muscle was reduced with age when palmitoyl-carnitine was used as substrate (heart: $10.5 \pm 1.4 \mu \mathrm{l} \mathrm{O} / \mathrm{mg}$ protein/hour for young hamsters, and $6.3 \pm 1.2 \mu \mathrm{l} \mathrm{O} / \mathrm{mg}$ protein/hour for old. Quadriceps: $3.5 \pm 0.5 \mu \mathrm{l} \mathrm{O} / \mathrm{mg}$ protein/hour for young hamsters, and $2.5 \pm 0.5 \mu \mathrm{l} \mathrm{O} / \mathrm{mg}$ protein/hour for old) $p<0.05$. There were no age differences in respiratory capacity with pyruvate-malate as substrate (Fig. 2).

\section{DISCUSSION}

As hamsters age, their levels of spontaneous activity decline. Although both environmental variables such as length of photoperiod [30] and somatic variables such as body fatness [10] exert an influence over the activity levels in young adult hamsters, it is unlikely that either of these variables interfered with our test of the hypothesis that the decline in spontaneous running reflects age-associated changes in the availability and pattern of fuel utilization during exercise. Our animals were kept under controlled lighting, and we have found no difference in the body fat content between senescent and young hamsters in other studies (to be published).

Neither of the two hypotheses tested in this study was confirmed. First, we did not find significant age differences in the pattern of metabolic fuels used during submaximal exercise. Muscle glycogen depletion was moderate and was unaffected by age. Neither did we find an effect of age on State 3 (ADP-stimulated) respiration of muscle homogenates with pyruvate-malate as substrate. Thus, under the condition of maximal in vitro rate of oxidation, cardiac and skeletal muscle from young and old hamsters have similar rates of carbohydrate oxidation. A moderate degree of muscle glycogen depletion, and absence of exercise-induced changes in circulating glucagon and catecholamine concentrations indi- cate that at 60 percent of $\mathrm{VO}_{2}$ max, carbohydrate use was slight. Two hours of treadmill running produces greater glycogen depletion in rats, yet it is unaccompanied by signs of fatigue [3]. Thus, it is more likely that at the submaximal pace of this study, hamsters relied more on the highly oxidative Type 1 motor units which utilize lipid fuels than on the glycolytic Type II motor units [12].

It is unlikely that reduced availability of lipid could account for the age-associated decline in spontaneous running activity in hamsters. Exercise-induced increases in free fatty acid and glycerol concentrations were unaffected by hamsters' age. While the in vitro release of glycerol is diminished from adipocytes of aged rats [16], and the ADP-stimulated maximal oxidative rate with palmitoyl carnitine as substrate was diminished in muscle homogenates of aged hamsters in this study, the submaximal pace of running in the present experiment was not likely to have led to intramuscular ATP depletion. Since State 3 respiration reflects the maximum rate of oxidation possible in vivo, the moderate exercise intensity used in this study was probably not of sufficient stimulus to cause the rate of ATP demand to exceed the rate of ATP production.

We have found no evidence that changes in the release of hormones responsible for fuel mobilization account for the age-associated decline in spontaneous running in hamsters. We observed no exercise-induced increases in serum glucagon or catecholamines in hamsters of either age group. It is possible that the pace of running selected for this study as well as the corresponding pace during spontaneous running activity in hamsters is too slow to induce catecholamine release. It is also possible that at this pace, depletion of muscle and liver glycogen is too low to induce glucagon release.

It is not clear whether the age-associated differences in tissue concentrations of glycogen, in blood glucose and in the concentrations of glucoregulatory hormones of nonexercised animals had any significance on reduced spontaneous activity levels of senescent hamsters. Thus, the reduced serum insulin concentration, increased plasma glucagon concentration, decreased concentration of glycogen in the liver and increased blood glucose of senescent hamsters may be indicative of incipient diabetic state. Old rats have also been reported to have reduced serum insulin concentration [28], a condition that results from greater decreases in insulin release than in the metabolic clearance of the hormone [27]. Weight declines in senescent animals may be related to reduced stimulation by insulin of tissue anabolism. Mean body weight of the old hamsters in this study decreased approximately 10 percent from 14 to 17 months of age. Further, exercise may have failed to suppress serum insulin concentration in old hamsters because of the already low levels of this hormone in their circulation.

Finally, a small decline in $\mathrm{VO}_{2}$ max in old hamsters in this study (less than half of the decline reported in old rats) [24], demonstrates that when old hamsters are forced to exercise to peak intensity very small age-associated decrements are revealed. In conclusion, neither reduced aerobic capacity nor altered pattern of substrate utilization during submaximal exercise can explain the marked age-associated reduction in spontaneous running activity in hamsters. 


\section{REFERENCES}

1. Asdell, S. A. and S. R. Josh. Reproduction and longevity in the hamster and rat. Biol Reprod 14: 478-480, 1976.

2. Astrand, P. O., A. Hallback and A. Kilborn. Reduction in maximal oxygen uptake with age. J Appl Physiol 35: 649-654, 1973.

3. Baldwin, K. M., J. S. Reitman, R. L. Terjung, W. W. Winder and J. O. Holloszy. Substrate depletion in different types of muscle and in liver during prolonged running. Am $J$ Phystol 225: $1045-1050,1973$.

4. Bergmeyer, V. Methods of Enzymatic Analysts, Vol 3. New York: Academic Press, 1974, pp. 1404-1408.

5. Bergstrom, J., L. Hermansen, E. Hultman and B. Saltın. Diet, muscle glycogen and physical performance. Acta Physol Scand 71: $140-150,1967$.

6. Berson, S. A., R. S. Yalow, S. M. Glick and J. Roth. Immunoassay of protein and peptide hormones. Metaboltsm 13: 35-40, 1964.

7. Beyer, R. E., J. W. Starnes, D. W. Edington, R. J. Lipton, R. T. Compton, III and M. A. Kwasman. Exercise-induced reversal of age-related declines of oxidative reactions, mitochondrial yield, and flavins in skeletal muscle of the rat. Mech Ageing Dev 24: 309-323, 1984.

8. Birt, D. F. and R. D. Conrad. Weight gain, reproduction, and survival of Syrian hamsters fed five natural ingredient diets. $L a h$ Anim Scl 31: 149-154, 1981.

9. Borer, K. T. Characteristics of growth-inducing exercise. Physiol Behav 24: 713-720, 1980.

10. Borer, K. T.. C. D. Potter and N. Fileccia. Basis for hypoactıvity that accompanies rapid weight gain in hamsters. Physol Behav 30: 389-397, 1983.

11. Brooks, G. A. and T. P. White. Determination of metabolic and heart rate responses of rats to treadmill exercise. J Appl Phystol 45: 1009-1015, 1978

12. Burke, R. E., D. N. Levine, F. E. Zajac, P. Tsaris and W. K. Engel. Mammalian motor units: physiological-histochemical correlation in three types in cats gastrocnemius. Science 174: 709-712, 1971.

13. Chen, J. C., J. B. Warshaw and D. R. Sanadi. Regulation of mitochondrial respiration in senescence. $J$ Cell Physiol 80: $141-148,1972$.

14. Consolazio, C. F., R. E. Johnson and L. T. Pecora. Physologucal Measurements of Metabolk Functions in Man. New York McGraw Hill, 1963, pp. 5-9.

15. Costill, D. L., W. J. Fink and P. J. Van Handel. Analytical Methods for the Measurement of Human Performance. Mun cie, IN: Ball State University, 1979, pp. 28-29.
16. Dax. E., J. Parlla and R. Gregerman. Mechanım of the agerelated decrease of epinephrine-stimulated hpolyus in isolated rat adipocytes adrenergic receptor binding, adenylate cyclase activity and cyclic AMP accumulation. J Lipd Re' 22: 934-943, 1981.

17. Goldsteın, D.. G. Feuerstein, J. Izzo, E. Kopin and H. Keısler. Valıdity and reliabılity of liquid chromatography with electrochemical detection for measurement of plasma levels of norepinephrine and epinephrine in man. Life $S_{c i}$ 28: 467-475, 1981.

18. Hansford, R. and F. Castro. Age-linked changes in the actıvity of enzymes of the tricarboxylic cycle and lipid oxidation, and of carnitine content in muscles of the rat. Mech Ae'ing De' 19: 191-201, 1982.

19. Hermanssen, L., E. Hultman and B. Saltın. Muscle glycogen during prolonged severe exercise. Acta Physiol Scand 71: 129 139, 1967.

20. Hooker. A. M. and K. M. Baldwin. Substrate oxıdation specificity in different types of mammalian muscle. Am J Physiol 236: C66-C69, 1979

21. Keppler, D. and K. Decker. Glycogen determination with amyloglucosidase. Methods of Enzymatic Analysis, Vol 3. New York: Academic Press, 1974, pp. 1127-1131.

22. Lowery, P. H. and J. Passoneau. A Flexible System of Ensymatı Analyus. New York: Academic Press, 1972, pp. 189-191.

23. Lowry, O. M.. N. J. Rosenbrough, A. L. Farr and R. J. Randall. Protein determination with the folin phenol reagent. $J$ Blol Che'm 193: 771-775, 1951.

24. Mazzeo, R. S., G. A. Brooks and S. M. Horvath. Effects of age on metabolic responses to endurance trainıng in rats. $I$ Appl Physiol 57: 1369-1374, 1984

25. Peck, S., S. Fajana, J. Floyd, R. Knopf and J. Kuhn. Falture of sulfonylureas to suppress plasma glucagon in man. Diabetes 21: 216-223, 1972.

26. Pernow, B. and B. Saltın. Avalability of substrates and capacity for prolonged heavy exercise in man. I Appl Physol 31: 416-422, 1971

27. Reaven, E., G. Gold and G. Reaven. Effect of age on glucosestımulated insulin release by the $\beta$-cell of the rat. $J$ Clin Invest 64: 591-599. 1979.

28. Roth. G. S., S. P. Tzankoff and D. Ekehi. Effects of age on control of lipolysis durng fasting. J Gerontol 36: 391-397, 1981.

29 Solonı, F G. A simplified manual micromethod for determination of serum triglyceride. Clin Chem 17: 529-534, 1971.

30. Widmaier, E. P. and C. S. Campbell. Interaction of estradiol and photopenod on activity patterns in the female hamster. Phwal Behav 24: 923-032, 1980 